\title{
LA INTERPRETACIÓN PATRIMONIAL EN EL MUSEO PEDAGÓGICO UNIVERSITARIO: HACIA UNA PEDAGOGÍA DE LA ESTAMPA HISTÓRICO EDUCATIVA ${ }^{1}$
}

\author{
Pablo Álvarez Domínguez \\ Universidad de Sevilla, España \\ pabloalvarez@us.es
}

\begin{abstract}
RESUMEN
Las universidades, en general, cuentan con un importante patrimonio científico e histórico que, además de conservar, tienen que difundir, facilitando su interpretación. De esta forma, a los museos pedagógicos universitarios, que se presentan en estos momentos como una atractiva y sugerente oportunidad cultural para conocer e interpretar la historia del pasado escolar, les corresponde abrir las puertas del universo cultural histórico educativo a toda la comunidad. Partiendo de que las fotografías del pasado educativo no son siempre fáciles de leer e interpretar, reivindicamos en este trabajo la necesidad de considerar una intermediación pedagógica entre las imágenes del ayer de la escuela, los contextos y las personas. El artículo, a través de un estudio de caso materializado en el Museo Pedagógico de la Facultad de Ciencias de la Educación de la Universidad de Sevilla, a modo de proyecto de innovación docente, intenta aproximarse a la redacción de las bases de una pedagogía de la estampa histórico educativa. Se trata de recrear desde el presente fotografías escolares del ayer, con el fin de crear conciencia patrimonial educativa entre los estudiantes de Ciencias de la Educación.
\end{abstract}

Palabras clave: Museos de Educación/Pedagógicos y Universidad, interpretación del patrimonio educativo, imágenes de la historia de la educación, fotografía escolar

\section{HERITAGE INTERPRETATION IN THE UNIVERSITY PEDAGOGICAL MUSEUM: TOWARDS A PEDAGOGY OF THE SCHOOL PHOTOGRAPHY}

\begin{abstract}
Universities have an important scientific and historical heritage must preserve, disseminate and interpret. Pedagogical University museums are an attractive and suggestive cultural opportunity to know and interpret the history of the last school. These museums allow us to open the doors of the historic cultural education universe to the community. Photographs of the educational past are difficult to read and interpret. In this work we defend the need to consider a pedagogical intermediation between images of the last school, scenarios, and people. The article presents a case study developed in the Educational Museum of the Faculty of Sciences of the Education of the University of Seville. It's a teaching innovation project, which aims to approximate to the bases of a pedagogy of educational historic photography. It consists of recreation from the school present photographs of the past, in order to create educational heritage awareness among students in Educational Sciences.
\end{abstract}

\footnotetext{
${ }^{1}$ Este trabajo está vinculado al desarrollo de una estancia de investigación enmarcada en el proyecto de investigación "Cultura escolar, patrimonio educativo y museos de educación: aportaciones desde la historia de la educación”. "Programa Becas Iberoamérica. Santander Investigación Universidades", convocatoria 2016/2017, subvencionado por el Banco Santander. Universidad Estadual de Campinas (UNICAMP). Campinas-Brasil.
} 
Keywords: Museums of Education /Pedagogical and University, interpretation educational heritage, images of the history of education, school photography

\section{A INTERPRETAÇÃO PATRIMONIAL NO MUSEU PEDAGÓGICO UNIVERSITÁRIO: RUMO A UMA PEDAGOGIA DA FOTOGRAFIA HISTÓRICO- EDUCATIVA}

\section{RESUMO}

As universidades possuem um importante patrimônio científico e histórico que precisam conservar, difundir e interpretar. Os museus pedagógicos universitários são uma atrativa e sugestiva oportunidade cultural para conhecer e interpretar a história do passado escolar. Esses museus nos permitem abrir as portas do universo cultural histórico educativo para toda a comunidade. As fotografias do passado educativo são difíceis de ler e interpretar. Neste trabalho, reivindicamos a necessidade de considerar uma intermediação pedagógica entre as imagens do passado escolar, os cenários e as pessoas. $\mathrm{O}$ artigo apresenta um estudo de caso desenvolvido no Museu Pedagógico da Faculdade de Ciências da Educação da Universidade de Sevilha. Trata-se de um projeto de inovação docente que pretende aproximar-se das bases de uma pedagogia da fotografia histórico-educativa. Consiste na recriação, a partir do presente, de fotografias escolares do passado, com a finalidade de criar consciência patrimonial educativa entre os estudantes de Ciências da Educação.

Palavras-chave: Museus de Educação/Pedagógicos e Universidade, interpretação do patrimônio educativo, imagens da história da educação, fotografia escolar.

\section{L'INTERPRÉTATION DU PATRIMOINE AU MUSÉE PEDAGOGIQUE DE L'UNIVERSITÉ: VERS UNE PÉDAGOGIE DE LA RECRÉATION DE L'IMAGE DE L'ÉCOLE}

\section{RÉSUMÉ}

Les universités ont un important patrimoine historique et scientifique qui doit être préservé, diffusé et interprété. Les musées pédagogiques de l'Université offre une opportunité attractive et prometteuse sur le plan culturel pour connaître et interpréter l'histoire de l'école. Ces musées nous permettent d'ouvrir les portes de l'univers culturel historique et éducatif à la communauté. Les photographies du passé éducatif sont difficiles à lire et à interpréter. Dans ce travail, nous défendons la nécessité d'envisager une intermédiation pédagogique entre les dernières images de l'école, les scénarios et les personnes. L'article présente une étude de cas, mise au point dans le Musée pédagogique de la Faculté des Sciences de l'Education de l'Université de Séville. C'est un projet d'enseignement innovant, qui vise à rapprocher les bases d'une pédagogie de la photographie historico-éducative. Il a pour but de recréer des photographies scolaires du passé en partant du présent, afin de sensibiliser les étudiants en sciences de l'éducation au patrimoine éducatif .

Mots clés: musées de l'Education/Pédagogique et Université, interprétation du patrimoine éducatif, images de l'histoire de l'éducation, photographie scolaire 


\section{INTRODUCCIÓN}

Universidad, museo, museo pedagógico, interpretación del patrimonio educativo y fotografía escolar, son cinco conceptos que estrechamente relacionados entre sí, darán sentido al trabajo que se presenta, en aras de poner en valor la importancia cultural que en la actualidad están adquiriendo los museos pedagógicos universitarios españoles en el desarrollo de su función educadora/didáctica.

La universidad surgió en Europa alrededor de los siglos XII y XIII a través de las escuelas catedralicias y monásticas. Su concepto, derivado del latín universitās magistrōrum et scholārium -comunidad de profesores y académicos-, se refiere en la actualidad y de acuerdo con la Real Academia Española, a una entidad orgánica o sistema de unidades operativas de enseñanza superior, investigación y creación de cultura científica y humanística. En la misma línea, un museo -del latín musēum y del griego Movøcíov-, es una institución pública o privada, permanente, con o sin fines de lucro, al servicio de la sociedad y su desarrollo, y abierta al público, que adquiere, conserva, investiga, comunica, expone o exhibe colecciones de bienes patrimoniales con propósitos de estudio y educación, y siempre con un valor cultural. Un museo pedagógico es un centro de interpretación de la cultura histórico educativa, vivo y activo -real o virtual-, dirigido a toda la sociedad, que ofrece conocimientos, información, oportunidades para emocionarnos, experiencias didácticas y posibilidades para garantizar el estudio, conservación, exposición, difusión e interpretación de cuantos bienes materiales e inmateriales conforman el patrimonio de la educación (ÁLVAREZ, 2016a). En este sentido, al intentar definir interpretación del patrimonio educativo, nos referimos al arte de traducir el lenguaje técnico, científico y complejo ligado al conjunto de bienes patrimoniales que nos ha legado la historia de la educación, a uno más coloquial, asequible y comprensible para las personas poco entendidas y no suficientemente interesadas en el pasado de la educación y de la escuela. Y en última instancia, cuando hablamos de fotografía escolar entendida como bien patrimonial histórico educativo, nos referimos al fruto de desarrollar un procedimiento y arte que permite fijar y reproducir las imágenes escolares que se han podido recoger en el fondo de una cámara oscura.

Considerados los anteriores conceptos -fundamentales para introducir este trabajo-, queremos hacer patente que a la universidad actual, en la que han influido diferentes corrientes filosóficas, religiosas, sociales, históricas, políticas y económicas imperantes en las distintas épocas de la humanidad (AGUANA FIGUEROA, 2013), aún le queda un largo camino por recorrer si quiere ser pionera en el desarrollo y gestión de la cultura. De esta 
forma, desde el punto de vista educativo nos encontramos con una institución que está obligada a constituirse como un centro destinado a la conservación, acrecentamiento y transmisión de la cultura. A la universidad del siglo XXI, no solo le compete generar y administrar cultura, sino que le corresponde transferirla a toda la sociedad a través del desarrollo de nuevas políticas culturales y de extensión e interpretación del conocimiento científico. Y no cabe duda, de que la universidad de nuestro tiempo encuentra en sus museos y colecciones científicas un importante acicate para acercar la ciencia y la cultura a la comunidad, facilitándole su interpretación. El patrimonio científico es una evidencia material de un legado colectivo común de la comunidad científica; se trata de aquello que la misma entiende como su propia identidad, que merece ser transmitida a las próximas generaciones de científicos y a sociedad en general, incluida todas las ciencias, incluso las humanidades (LOURENÇO y WILSON, 2013).

En este contexto, y reconociendo la relevancia e idiosincrasia del patrimonio histórico y científico de las universidades, en general, entendemos que aunque son muchas las tareas que se vienen desarrollando en lo que respecta a la identificación, catalogación, diagnóstico y exposición de las colecciones universitarias, aún les queda bastante por hacer en lo que atañe a la puesta en valor, difusión e interpretación (BRUNELLI, 2014a) de las mencionadas. La educación patrimonial sigue siendo una asignatura pendiente, a la que hay que dedicar un lugar especial, sobre todo en estos tiempos en los que la transferencia del conocimiento a la sociedad es uno de los objetivos fundamentales que tiene encomendado la universidad del siglo XXI. La investigación universitaria, entendida como proceso orientado a la generación de nuevos conocimientos, precisa verse complementada con una potente divulgación, concebida como la transmisión del conocimiento a toda la ciudadanía, sin discriminación de sus receptores.

De esta forma, entendemos que la universidad -como espacio de extensión cultural que debe ser-, ha de apostar fuertemente por contribuir a la educación de la ciudadanía a través de sus colecciones científicas y debe esforzarse por dotar de sentido al desarrollo de los procesos didácticos curriculares y extracurriculares, que tengan en cuenta al patrimonio como el principal motivo para la difusión del conocimiento científico. Justamente, ante este marco de actuación, los museos pedagógicos universitarios -como gestores y difusores de la cultura patrimonial histórico educativa-, se presentan en la actualidad como novedosos recursos didácticos al servicio de la investigación y la docencia en Historia de la Educación.

Actualmente, conscientes de que la enseñanza universitaria está en un momento de transformación y búsqueda de un nuevo sentido del conocimiento urgido por la necesidad de 
innovar, la demanda de calidad y el reto de la creatividad, justificamos la importante labor a la que han de hacer frente los museos pedagógicos desde la universidad. A este respecto, estos espacios están llamados a contribuir a un cambio de la docencia universitaria en Ciencias de la Educación, a través de lo que está más próximo al profesorado: sus estrategias y sus recursos didácticos.

En la actualidad, las Facultades de Educación españolas que tienen la suerte y el privilegio de contar con un museo pedagógico, han encontrado en ellos un atractivo y sugerente recurso investigador y docente, que está permitiendo transmitir significativamente todos aquellos contenidos que están ligados a la enseñanza de la Historia de la Educación, como disciplina que forma parte de los planes de estudio de los futuros profesionales del magisterio y la pedagogía. En estos momentos, partimos de la idea de que los museos pedagógicos universitarios están siendo capaces de seducir notablemente al alumnado de Ciencias de la Educación, en la medida en que a través de sus colecciones patrimoniales histórico educativas y sus novedosas propuestas didácticas para enseñar Historia de la Educación, facilitan un aprendizaje más revelador, constructivo, creativo y emocional.

Para el desarrollo de este trabajo, hemos elegido la metodología del estudio de casos. Stake nos recuerda que su particularidad reside en la comprensión de la realidad objeto de estudio. Así, el estudio de casos se concibe como "el estudio de la particularidad y de la complejidad de un caso singular, para llegar a comprender su actividad en circunstancias importantes" (STAKE, 2005, p. 11). Desde una perspectiva interpretativa, y de acuerdo con Pérez Serrano (1994, p. 81) entendemos que "el objetivo básico de esta metodología reside en comprender el significado de una experiencia”. Así, nos proponemos emprender un estudio de caso evaluativo, que conlleva una fundamentación teórica previa, y después una descripción y una explicación que nos permita emitir una serie de juicios sobre la realidad objeto de estudio. En nuestro caso concreto, nos interesa el conocimiento de lo particular, de lo idiosincrásico, sin dejar a un lado su contexto. Y además, pretendemos investigar el desarrollo y efecto de una práctica didáctica contemporánea dentro de su contexto real (YIN, 1989), tratando de enfrentarnos al "examen de un ejemplo en acción" (WALKER, 1983, p. 45). Nuestro interés radica en esta ocasión en describir el resultado de una conducta observada, dentro del marco de un determinado hecho circundante. Es por ello que basamos nuestra preocupación por la perspectiva de los participantes para identificar como participan y construyen el conocimiento y su realidad (CEBREIRO LÓPEZ y FERNÁNDEZ MORANTE, 2004, p. 665).

Este artículo, desde las anteriores consideraciones y concebido pues como un estudio de caso heurístico (los estudios de caso tratan de iluminar la comprensión del lector sobre el 
fenómeno objeto de estudio), se plantea con el propósito de dar a conocer un modelo innovador de buena práctica didáctico patrimonial, que viene desarrollándose en concreto en el marco del Museo Pedagógico de la Facultad de Ciencias de la Educación de la Universidad de Sevilla (ÁLVAREZ, REBOLLO y NÚÑEZ, 2016) desde su fundación en octubre de 2012 y hasta la actualidad. El trabajo que se presenta, a partir de la descripción, análisis y evaluación de un proyecto pedagógico, se propone sentar las bases del desarrollo de una pedagogía de la estampa histórico educativa, consistente en la recreación desde el presente y por parte del alumnado, de un conjunto de fotografías escolares del ayer, con el fin de aprender conocimientos histórico educativos y crear conciencia patrimonial escolar entre aquellos estudiantes de la Universidad de Sevilla que cursan las asignaturas de "Historia de la Educación Contemporánea" en el Grado en Pedagogía y “Corrientes Contemporáneas de la Educación. Implicaciones en la etapa infantil”’3, en el Grado en Educación Infantil.

\section{LOS MUSEOS PEDAGÓgICOS UNIVERSITARIOS Y SU POTENCIAL COMO CENTROS DE INTERPRETACIÓN DE LA CULTURA ESCOLAR}

La universidad como institución cultural y socioeducativa es un ente especialmente complejo, que tiene encomendada la función de escudriñar la realidad en sus diferentes ámbitos y manifestaciones, con la intención de desvelarla críticamente a toda la comunidad. En España, la Ley Orgánica de Universidades (LOU), en su reforma de abril de 2007, en su título XIV, artículo 93, titulado "De la cultura universitaria", nos recuerda que es responsabilidad de la universidad conectar al universitario con el sistema de ideas vivas de su tiempo, su espacio y su contexto. De esta forma, se les encomienda la tarea de gestionar los medios necesarios para potenciar su responsabilidad con la reflexión intelectual, la creación, la transferencia del conocimiento y la difusión cultural. Así, las universidades han de promover el acercamiento de las culturas humanística y científica, esforzándose por transmitir el conocimiento a la sociedad a través de lo que se ha venido a denominar divulgación e interpretación de la ciencia. Y en consecuencia, no cabe duda de que estas instituciones merecen ocupar un papel central en el desarrollo cultural de nuestros países.

Aceptando en la actualidad un cambio de paradigma en la función cultural de la Universidad (ARIÑO VILLAROYA, 2007), que tiene que ver, entre otras cosas, con la

\footnotetext{
${ }^{2}$ Cfr. http://www.us.es/estudios/grados/plan_174/asignatura_1740014 Programa de la asignatura.

${ }^{3} \mathrm{Cfr}$. http://www.us.es/estudios/grados/plan_194/asignatura_1940003 Programa de la asignatura.
} 
deriva de la cultura hacia el entretenimiento y con el marcado carácter interactivo y creativo de las audiencias, la universidad moderna se presenta como un prometedor espacio para la innovación científica. Y cuando planteamos esta reflexión, la hacemos entendiendo que tanto la innovación como la tecnología, no pueden resultarles ajenas a las ciencias sociales y humanas.

Los museos universitarios con sus colecciones científicas a la cabeza, han experimentado desde principios del siglo XXI un renovado interés de carácter generalizado. Aunque múltiples problemas asociados con los museos universitarios y sus colecciones científicas, y con el patrimonio universitario, en general, han existido desde tiempo atrás, es verdad que en la última década es cuando se ha hecho patente un progresivo interés por lo que atañe a estos asuntos. Lo que se pone de manifiesto, precisamente, a través de la creación de la Red Europea de Patrimonio Universitario UNIVERSEUM ${ }^{4}$-fundada en el año 2000 para ocuparse del patrimonio universitario europeo en su conjunto-, y del Comité de Museos y Colecciones Universitarias (UMAC) ${ }^{5}$ del ICOM, creado en 2001, para centrarse en reivindicar y guiar las necesidades de los museos y colecciones universitarias de todo el mundo. Gracias a ambas entidades, los museos universitarios y sus colecciones científicas gozan en la actualidad de un importante papel y reconocimiento en el desarrollo de la dimensión cultural a la que han de hacer frente nuestras universidades.

Los museos universitarios y sus colecciones científicas son excelentes ventanas abiertas a la investigación y a la enseñanza en la universidad, con capacidad más que suficiente para proporcionar ocasiones y oportunidades ligadas a la difusión de la cultura, la ciencia y la tecnología (SOUBIRAN, 2007, p. 41).

En los últimos tiempos, muy especialmente, y moviéndose a caballo entre la memoria y la creatividad, un importante grupo de universidades españolas han venido apostando por poner en valor a través de la creación de museos pedagógicos, el rico y significativo

\footnotetext{
${ }^{4}$ Cfr. http://universeum.it/about.html Página web de UNIVERSEUM. European Acedemic Heritage Network. Entre sus principales objetivos se encuentran los de: fomentar la reflexión y la investigación para mejorar nuestro conocimiento sobre el patrimonio universitario europeo; prestar apoyo en su preservación, cuidado y promoción; proporcionar un foro europeo para proyectos colaborativos que permitan compartir experiencias y conocimientos; establecer vínculos entre las instituciones europeas y las universidades en relación con su patrimonio; fomentar la creación de redes nacionales en Europa orientadas a la preservación, estudio y promoción del patrimonio universitario europeo; y, finalmente, promover el uso de este patrimonio para la investigación y la enseñanza.

${ }^{5}$ Cfr. http://umac.icom.museum Página web de UMAC (Comité internacional para los museos y las colecciones universitarias). El UMAC permite un debate abierto a todos los profesionales que trabajan en el sector de los museos, de las galerías y de las colecciones universitarias. Se interesa por el papel de las colecciones conservadas dentro de establecimientos de enseñanza superior y por las comunidades a las que se dirigen. Propone a sus miembros un foro de discusión que les permite identificar las posibilidades de colaboraciones con respecto a las colecciones, la repartición de los conocimientos y de las experiencias, así como al acceso a las colecciones. Su objetivo principal se concreta en proteger el patrimonio del que se encargan las universidades.
} 
patrimonio histórico educativo con el que cuentan nuestros pueblos y ciudades. Sin duda, se trata de un original y novedoso trabajo arqueológico, etnográfico y hermenéutico de carácter histórico educativo, fruto de manera particular del compromiso y esfuerzo académico e investigador de un nutrido equipo de historiadores/as de la educación. Afortunadamente, un amplio grupo de profesores/as ha sido capaz de tomar conciencia cultural universitaria, en relación con la necesidad de salvaguardar, conservar y exponer una muestra importante del patrimonio de la educación, entendido como el conjunto de restos materiales, objetos y huellas de interés cultural que nos ayudan a conocer el pasado histórico de la educación. Mayordomo Pérez (2016), nos recuerda que "el patrimonio material e inmaterial de nuestro sistema escolar, es una parte importante e ineludible del patrimonio cultural y de lo que significa la memoria colectiva" (p. 13). A este respecto, conviene considerar que esta última se va formando con la suma de memorias individuales, que se van enlazando para dar lugar a nuestra historia local, a nuestra intrahistoria. La memoria colectiva hace referencia a los recuerdos y memorias que atesora y destaca la sociedad en su conjunto; es compartida, transmitida y construida por el grupo o la sociedad (HALBWACHS, 1925).

$\mathrm{Y}$, en este escenario, los museos pedagógicos universitarios surgen en la era actual con la pretensión de ser espacios abiertos y vivos capaces de favorecer el estudio, catalogación, investigación, conservación, protección, uso didáctico y difusión del patrimonio histórico educativo. Estos museos, concebidos como espacios intergeneracionales e interidentitarios (PINTO, 2015) que pueden ser visitados por investigadores, docentes, profesionales, estudiantes y el público interesado en general, aspiran a contar con la participación activa de toda la sociedad, todas las personas y las diferentes entidades que lo deseen, para llegar a ser con esta colaboración-, una zona compartida de la memoria educativa.

En la actualidad, en España cuentan con un museo pedagógico las Universidades de Huelva $^{6}$, La Laguna ${ }^{7}$, Complutense de Madrid $^{8}$, Murcia ${ }^{9}$, País Vasco ${ }^{10}$, Salamanca ${ }^{11}$, Sevilla $^{12}$, Valencia ${ }^{13}$ y Vic. Se trata de museos presenciales y en un par de casos virtuales -

\footnotetext{
${ }^{6} \mathrm{Cfr}$. http://www.uhu.es/museopedagogico/ Página web del Museo Pedagógico de la Universidad de Huelva.

${ }^{7}$ Cfr. http://museoedu.webs.ull.es/ Página web del Museo de la Educación de la Universidad de La Laguna.

${ }^{8} \mathrm{Cfr}$. http://pendientedemigracion.ucm.es/info/muscosio/ Página web del Museo Laboratorio Manuel Bartolomé Cossio de la Universidad Complutense de Madrid.

${ }^{9}$ Cfr. http://www.um.es/web/ceme/ Página web del Centro de Estudios sobre la Memoria Educativa (CEME) de la Universidad de Murcia.

${ }^{10} \mathrm{Cfr}$. http://www.ehu.eus/es/web/museoeducacion Página web de Museo de la Educación de la Universidad del País Vasco.

${ }^{11}$ Cfr. http://campus.usal.es/ cemupe/ Página web del Centro Museo Pedagógico de la Universidad de Salamanca.

${ }^{12}$ Cfr. http://institucional.us.es/museopedagogia/ Página web del Museo Pedagógico de la Facultad de Ciencias de la Educación de la Universidad de Sevilla.
} 
MUVIP $^{14}$ y MUVHE ${ }^{15}$ - (ÁLVAREZ DOMÍNGUEZ, 2016a), que juntos vienen desarrollando una importante labor en el estudio, conservación y difusión del patrimonio y memoria individual y colectiva de la educación.

En estos momentos, no cabe duda de que estos museos gozan de un potencial significativo para propiciar la interpretación de la cultura escolar por parte de la ciudadanía. No obstante, conviene tener en cuenta una serie de consideraciones ligadas a lo que supone interpretar, entendida esta función como revelación de las características y del significado del bien patrimonial que se visita $\mathrm{y} / \mathrm{u}$ observa. Según la Real Academia Española, la interpretación -del latín interpretāri-, conlleva: "dar o atribuir a algo un significado determinado; explicar o aclarar el sentido de algo; expresar de un modo personal la realidad". Interpretar supone el desarrollo de un conjunto de acciones que tienen que ver con comentar, revelar, glosar, deducir, analizar, entender, descifrar, ilustrar, traducir, etc. Y además, conlleva valorar críticamente lo que vemos, comprendiendo los significados de las cosas que nos rodean. De esta forma, podemos intuir que la interpretación es todavía más difícil que la comprensión, porque ciertamente la incluye.

En el marco de un museo pedagógico universitario, interpretar supone además de tomar conciencia y darse cuenta, percibir el patrimonio educativo que tenemos a la vista. Se trata de emprender un ejercicio de investigación, evaluación y concienciación personal, que nos ayude a plantearnos una serie de interrogantes para poder descifrar los secretos, huellas y silencios que esconde la caja negra de la escuela, atribuyendo a cada pieza, recuerdo, testimonio, etc. su particular significado. Los visitantes de los museos pedagógicos -en aras de poder enfrentarse a una sobresaliente interpretación de la cultura material e inmaterial de la escuela-, necesitan metafóricamente hablando, ojos inteligentes para mirar y seleccionar con criterio; oídos abiertos para escuchar en medio del silencio; manos delicadas y curiosas para elevar el sentido del tacto al máximo exponente; olfato hábil para desarrollar una pedagogía de la intuición; gusto estético que se deje llevar por lo bello por encima de lo útil; y alma frágil para dejarse seducir por el mundo de las emociones y de los sentimientos. Un museo pedagógico universitario, concebido como centro de interpretación histórico educativo, tiene que ser mucho más que un ente meramente informativo. Además tiene que procurar no convertirse en un espacio aburrido y no llegar a dar una imagen pedante -histórica y

$13 \mathrm{Cfr}$. http://www.uv.es/uvweb/departamento educacion comparada historia educacion/es/seminario-museohistoria-escuela/presentacion-objetivos-1285875367517.html Página we del Seminario-Museo de Historia de la Escuela de la Universidad de Valencia.

${ }^{14} \mathrm{Cfr}$. https://www.uvic.cat/es/muvip Página del Museo Universitario Virtual de Pedagogía (MUVIP).

${ }^{15}$ Cfr. http://www.um.es/muvhe/user/ Página del MUVHE. Museo Virtual de Historia de la Educación. 
pedagógicamente hablando-, impidiendo con ella incluso la comprensión por parte del visitante. Resta señalar también que sus instalaciones no deben aspirar a convertirse en auténticos espectáculos socioambientales, pues con ellos solamente se conseguirá desenmascarar los mensajes que se desean transmitir. Lo mismo ocurrirá si seguimos pensando en que cuanta más información hagamos llegar al visitante, más aprenderán (MORALES MIRANDA, 1994). Un museo pedagógico con lecciones histórico educativas escritas en sus paredes a modo de libro, no podrá aspirar a convertirse más que un espacio literario al servicio de un público especializado en el estudio e interpretación de la cultura escolar. Un museo pedagógico diseñado como centro para el visitante en el espacio universitario, será siempre una excelente ocasión para acercar el patrimonio educativo a la comunidad y para estimularla a una constante interpretación del hecho histórico educativo. Este espacio hay que entenderlo como un lugar de memoria y para la memoria educativa, que sea capaz de integrar como objetivos fundamentales la custodia, conservación, difusión e interpretación de los objetos, ideas y valores pedagógicos de una sociedad. En él, a veces puede ocurrir que no sea la calidad o el carácter único de la pieza histórico educativa lo que más interese, sino que por el contrario, nuestra atención venga atribuida a su manifestación anónima como expresión popular y elemento identificador de la cultura patrimonial histórico educativa.

Si conseguimos que nuestros museos pedagógicos sean espacios notablemente visitados en nuestras universidades, no podemos marginar todo aquello que tiene que ver con la necesidad de hacerlos comprensivos a toda la sociedad. De esta forma, no cabe duda de que el reto de facilitar la interpretación del patrimonio escolar que nos rodea, nos puede ayudar a percibir los confines del universo cultural histórico educativo del que formamos o hemos formado parte. En nuestro caso particular, debemos aspirar a construir museos pedagógicos más comprensibles por todos, pues con ello, estaremos garantizándonos un mayor número de visitantes. No podemos construir meros museos expositivos en los que la descontextualización de objetos, artefactos o imágenes sea la tónica dominante; y es por esto que entendemos especialmente importante el enriquecernos con las posibilidades que nos brinda la interpretación patrimonial como disciplina encargada de garantizar la traducción del lenguaje técnico y a veces complejo del legado histórico educativo, cultural y patrimonial educativo, a una forma sencilla y comprensible para todos los públicos (ÁLVAREZ DOMÍNGUEZ, 2016b).

El estudio de la cultura histórico educativa en general, y de la escolar en particular, supone un intento justificado, coherente y lógico, de esclarecer elementos y aspectos de la 
misma en tiempos pasados, pues, ciertamente, "el mundo escolar posee normas, códigos, rasgos y prácticas diferentes a la estructura social general que, sin aislarse de un contexto global al que pertenece, conforma una cultura con señas de identidad diferenciadas" (LÓPEZ MARTÍN, 2001, p. 12). Los museos pedagógicos tienen el privilegio de contar con un patrimonio que no le puede resultar ajeno a ningún sector de la sociedad, pues todos hemos pasado en nuestras vidas por algún tipo de escolarización más o menos formal. Es precisamente por ello, por lo que las universidades han de aprovechar la oportunidad de acercar una parte de la cultura a la sociedad a través de actividades, propuestas y ejercicios interpretativos vinculados al estudio de la Historia de la Educación y el patrimonio educativo. El museo pedagógico, al tomar conciencia de su misión como intérprete activo del patrimonio escolar y como educador de público, ha de seguir asumiendo la necesidad de convertirse en un atractivo centro de proyección interpretativa sobre su entorno social.

En definitiva, uno de los retos actuales de nuestros museos pedagógicos universitarios reside en facilitar una verdadera interpretación del patrimonio histórico educativo a los estudiantes de Ciencias de la Educación y a toda la sociedad, a través de interesantes proyectos didácticos e interpretativos que consigan sensibilizarlos en el estudio, conservación y difusión del patrimonio histórico educativo. En esta línea, conviene no olvidar que la tarea de interpretar este patrimonio tiene que ver con el arte de revelar in situ al visitante el significado de la herencia cultural histórico educativo que se nos ha legado.

\section{LA INTERPRETACIÓN DEL PATRIMONIO FOTOGRÁFICO ESCOLAR COMO PRÁCTICA CREATIVA EN LA UNIVERSIDAD}

En la sociedad actual, la universidad a la que aspiramos tiene que ver con una institución con capacidad suficiente para la gestión y el desarrollo de estrategias creativas en su organización, en sus espacios culturales y en sus aulas. Si bien es cierto que una universidad debe ser un espacio cultural para la creatividad, también es verdad que es bastante cuestionable el lugar que ocupa la misma en ella. Considerando que las universidades en general, no son todo lo creativas que creen ser, entendemos que la universidad actual precisa de espacios constructivos e inspiradores, donde se pueda desarrollar la competencia creativa, la libertad de pensamiento, la crítica con fundamento, el emprendizaje inteligente, la internacionalización del conocimiento, el desempeño de nuevos roles y competencias, etc. La creatividad en el desarrollo de los procesos didácticos universitarios nos permite ofrecer nuevas propuestas y soluciones a tradicionales formas de hacer y de pensar las cosas. Una 
universidad creativa e imaginativa es una institución que produce y genera ideas novedosas constantemente, estando dispuesta a invertir tiempo y recursos para su desarrollo (BARNETT, 2013).

Las instituciones universitarias de la sociedad actual están llenas de profesorado cuya función principal en lo que a actividad docente respecta, se limita a explicar y transmitir a través de lecciones magistrales, repitiendo las mismas informaciones extraídas cada curso de viejos libros, sin tomar conciencia de que los estudiantes de la era vigente necesitan aprender con nuevas estrategias, recursos y escenarios mucho más atrayentes, sugerentes e insinuantes. En cualquier caso, y como señala de la Torre, $(2009$, p.3), lo que hay que remover en este sentido, "no es tanto la práctica pedagógica, cuanto la visión positivista y fragmentada del conocimiento que subyace a la misma". Con el Plan Bolonia, aunque con escasos recursos, se nos viene exigiendo pasar de una enseñanza basada en la información que transmite el profesorado a una enseñanza basada en la actividad formativa del alumnado. De esta forma, tenemos que reconocer que con Bolonia sí que se han presentado en la universidad nuevas oportunidades que han posibilitado una mejora importante en la metodología docente universitaria. Así, hemos avanzando en la solidificación de una enseñanza basada en la autonomía del estudiante, en la interacción profesorado-alumnado, en la implicación personal y en la aplicación de estrategias didácticas innovadoras y creativas. En este sentido, queremos destacar el papel que adquieren los espacios dialógicos y reflexivos, junto con nuevos escenarios de enseñanza aprendizaje paralelos al aula.

En lo que atañe a la enseñanza de la Historia de la Educación en contextos académicos universitarios, y tal y como se ha puesto de manifiesto en el apartado anterior, contamos con el museo pedagógico como un nuevo escenario didáctico que nos está ayudando a forjar en el alumnado un pensamiento histórico educativo más crítico, interpretativo, fundamentado y contrastado. A través de los museos pedagógicos universitarios estamos tratando de entusiasmar e inducir a los estudiantes hacia un autoaprendizaje más experiencial y emocional, haciéndoles más atractivos y apetecibles los contenidos histórico educativos contemporáneos que nos corresponden transmitir. De esta forma, a través de múltiples prácticas didácticas desarrolladas en el marco del museo, el alumnado está empleando en aprender un tiempo importante -en muchos casos hasta más del habitual-, sin que ello les pese. Por el contrario, los estudiantes disfrutan aprendiendo porque tienen la oportunidad de realizar aportaciones personales en el marco del desarrollo de proyectos individuales y grupales, de crear y de recrear nuevos aprendizajes, de transferir lo aprendido a otras situaciones, y de internacionalizar las experiencias construidas a través de las posibilidades 
que nos brindan las nuevas tecnologías (PAYÀ y ÁLVAREZ, 2015), entre otras cuestiones. De alguna manera, somos conscientes de que la creatividad docente ha de radicar en dejar huella en el alumnado, dejar impronta, de tal forma que en el futuro y una vez que pase el tiempo, se recuerden a aquellos profesores que supieron trasmitir algo más que información (DE LA TORRE, 2009) y que pusieron nuevos recursos creativos al servicio del aprendizaje universitario, cuyo caso nos ocupa.

La civilización visual en la que nos encontramos inmersos nos reta continuamente al profesorado universitario de Historia de la Educación al uso de fuentes icnográficas para el desarrollo de la investigación y la docencia histórico educativa. La fotografía, al igual que otras manifestaciones artísticas, se ha convertido en referente creativo para descubrir esta historia desde nuevos ángulos y enfoques (VILLA, 2015). Así, las fotografías escolares nos permiten visualizar la cultura material de la escuela, que la constituye un conjunto de objetos que portan significados que nos corresponden descifrar a través de indicios que hay que sugerir a quien observa. Cuando hablamos de fotografía escolar, nos referimos a "una gran diversidad de imágenes manifestadas de formas diversas y relacionadas con el espectro escolar como denominador común” (GONZÁLEZ y COMAS, 2016, p. 218). Así, como señala Sanchidrián (2011, p. 295), estamos de acuerdo en que el uso de imágenes debe permitirnos hacernos nuevas preguntas que vayan más allá de la mera descripción del escenario educativo, permitiéndonos ampliar los espacios y los tiempos que podemos estudiar.

Estas fotografías, entendidas como memorias de diferentes miradas histórico educativas (RIEGO, 2001), nos ayudan a descifrar e interpretar las huellas del pasado en las culturas escolares y a construir, reconstruir y representar las prácticas escolares en el aula (DEL POZO ANDRÉS, 2006). No obstante, tenemos que ser conscientes de que no se pueden entender las imágenes sin un extenso conocimiento de la cultura que las produce. Las fotografías, como señala Velasco (2012, p. 20), "inevitablemente, son selecciones incompletas de imágenes y fragmentos de realidades que difícilmente pueden ser compuestos y encajados unos con otros". De alguna forma, el patrimonio fotográfico escolar desde los museos pedagógicos, nos ayuda a hacer visible los objetos de la escuela, proporcionándonos pistas sobre su significado en el contexto educativo de origen. Además, estas imágenes -concebidas como estampas pedagógicas/escolares de carácter histórico-, nos ayudan a visibilizar silencios y ausencias materiales ocultas a lo largo de los tiempos históricos de la escuela (DEL POZO y RABAZAS, 2012, p. 408-409). Como señalan González y Comas (2016, p. 215), "la escuela y su contexto nos han dejado un elevado número de fotografías cuyo valor, tanto desde la 
perspectiva patrimonial como historiográfica, poco a poco va adquiriendo su justo reconocimiento".

Las fotografías son objetos culturales, hechas para proyectar significados y provocar efectos (GROSVENOR y ROUSMANIERE, 2016, p. 257). La foto escolar es un producto cultural que genera un discurso propio susceptible de análisis e interpretación desde el punto de vista histórico educativo; por ello, un análisis interpretativo de las fotografías escolares puede ayudarnos a comprender mejor la historia. La fotografía escolar tiene una innegable capacidad evocadora de los recuerdos de la escuela, que pueden ser tanto positivos como negativos. Se trata de un medio que nos permite conservar recuerdos escolares a través de imágenes y de un atractivo recurso pedagógico que nos permite comprender, asociar, comparar, imaginar, relacionar, interpretar y transferir ideas y conceptos vinculados con el estudio del pasado de la institución escolar.

La fotografía en este caso, nos interesa especialmente por lo que nos puede decir del pasado de la escuela; se transforma en un documento sensible que puede tener interpretaciones variadas, estimulando una respuesta sobre la memoria y la historia de los lugares, los espacios, las personas, los objetos, las identidades, etc. La fotografía escolar, no deja de ser un documento presumiblemente complejo de importante dimensión social (BRUNELLI, 2014b), que permite establecer un diálogo entre actores con la mirada entre el pasado y el presente de la escuela. La visión del ayer plasmada en un documento fotográfico de carácter histórico educativo, precisa de quien observa una serie de conocimientos históricos ligados a las diferentes cuestiones plasmadas en ella. Nos referimos, por ejemplo, a la zona geográfica en la que se encuadra la historia que se retrata, a las personas fotografiadas, a las tradiciones escolares, a los materiales utilizados, a las connotaciones políticas, sociales, culturales, religiosas, etc.

Tal y como se pone de manifiesto en el programa "Memoria de la Educación Argentina, de la Biblioteca Nacional de Maestros (2012), la foto en el ámbito de la escuela permite recuperar la mirada que ella tiene de las diferentes dimensiones en las cuales se desarrolla la infancia. Nos referimos a la mirada sobre lo familiar, sus rostros, los tiempos, las organizaciones, los rituales, los avatares familiares; miradas sobre lo escolar como el tiempo en la escuela, la arquitectura escolar, los espacios escolares, la recreación, el trabajo, los valores, las producciones culturales, textuales y simbólicas. 
retratado, qué aspectos del presente estén en ese pasado y viceversa. La fotografía tiene muchos discursos, tantos como intereses pueda despertar en su interlocutor. Así, la importancia de conservar el patrimonio fotográfico está dada en tanto que la foto señala y vincula lugares con sucesos, por lo cual se transforma en un documento que constituye identidad. En tal sentido la fotografía posee un carácter documental que le da un valor patrimonial y un sentido identitario particular y distintivo. Difundir fotos que hayan pertenecido a tiempos pasados cobra importancia porque el conocimiento de dichas imágenes, las cuales ilustran el contexto, permite identificarnos con vínculos de diferentes índoles a través del tiempo, y genera una relación de identidad y pertenencia al lugar (BIBLIOTECA NACIONAL DE MAESTROS, 2012, p. 5-9).

Las fotografías tienen una vida cultural, nos miran y nos interpelan, ocultan unas cosas y muestran otras, y sus contenidos cambian con el tiempo para los observadores y para lo observado. En lo que atañe a las más antiguas además, de acuerdo con Velasco (2012, p. 19), nos ayudan a trasladar espacios, objetos y personas de los tiempos antiguos a los nuevos como intentos de recuperar realidad, estimulando el contraste y el ineludible cotejo con la situación actual. De esta forma,

El efecto de producción de memoria que la etnografía detecta, conlleva aplicar el enfoque performativo de hallar, volver a ver las fotografías y revivir las escenas escolares y los acontecimientos pasados en ellas. Son esas también las huellas que las instituciones pensaban que iban a quedar en las sucesivas generaciones de alumnado. El enfoque performativo enlaza atinadamente con la idea de que los patrimonios fotográficos, como otros patrimonios culturales, tienen vida propia, una vida social. (VELASCO, 2012, p. 20).

La performance, y con ella la estética de lo performativo (FISCHER, 2011), tiene motivos para configurarse tanto en la universidad como en el museo pedagógico como un contenido metodológico con múltiples posibilidades educativas La performance es una modalidad del arte en acción individual o colectiva, entendida como una experiencia intersensorial, en la cual no solo participan vista y oído, sino que también lo hacen el tacto, el gusto, el olfato, la luz, el color, el movimiento, la música y otros efectos visuales. Señalado lo cual, queremos entender que el arte de acción puede contribuir a desarrollar la creatividad del estudiante universitario, ampliando e intensificando a la vez su experiencia estética (GOMÉZ ARCOS, 2005).

El impulso creativo es el motor que nos mueve hacia un aprendizaje más significativo, tanto en cuanto posibilita explorar ideas, plantear problemas e interrogantes, reunir informaciones, interpretar la realidad desde diferentes perspectivas, tomar decisiones, etc. Los actos creativos surgen del impulso de y necesidad de comunicar algo a los demás. A través de la creatividad el ser humano conoce el mundo e intenta definir su lugar dentro del mismo. Si queremos adultos creativos, estamos obligados a dejar hueco en el aula para el desarrollo de la creatividad. Los aprendizajes heterodoxos impiden este ejercicio fundamental en la vida de las 
personas. Desde la universidad tenemos que enseñar a captar las posibilidades ocultas del contexto y del mundo en el que nos encontramos. Salir de la rutina, de lo mecánico, de lo tradicional, no es más que un reto posible, si para alcanzarlo nos aliamos a la creatividad como ente pedagógico. Nuestras acciones didácticas en el contexto universitario precisan de metáforas vivenciales que nos ayuden a recrear e interpretar contextos, espacios, escenas, situaciones, cultura, etc. Nuestros estudiantes precisan aprender de ellos mismos ante el espectáculo de sus propias acciones. Registrar y percibir uno desde fuera su propia acción, como si de un espectáculo se tratase, ayuda a tomar conciencia de la realidad, provocando una reflexión crítica sobre lo hecho (TRACHANA, 2013).

Así, al museo pedagógico universitario, en aras de propiciar la interpretación de la fotografía, del patrimonio fotográfico escolar, se le presenta un futuro prometedor por delante, tanto en cuanto sea capaz de participar activamente en el desarrollo de importantes procesos docentes de carácter creativo y constructivo, a través de lo que hemos venido a llamar "pedagogía de la estampa histórico educativa". A los museos pedagógicos universitarios les corresponde en este sentido facilitar un aprendizaje lúdico, que unido al trabajo científico, heurístico y creador, permita al estudiante aprender placenteramente.

\section{LA PEdagogía de LA ESTAMPA Histórico EdCATIVA EN EL MUSEO PEDAGógICO DE LA FACULTAD DE CIENCIAS DE LA EDUCACIÓN DE LA UNIVERSIDAD DE SEVILLA}

El Museo Pedagógico de la Facultad de Ciencias de la Educación de la Universidad de Sevilla ${ }^{16}$, es un espacio universitario compartido, de carácter docente e investigador, con sede física en la mencionada Facultad, cuyas funciones principales son las de adquirir, reunir, ordenar, documentar, archivar, proteger, conservar, estudiar y exponer de manera didáctica una muestra representativa de cuantas piezas y elementos conforman el patrimonio educativo (ÁLVAREZ, REBOLLO y NÚÑEZ, 2016). Desde su fundación en 2012, grandes han sido sus esfuerzos por convertirlo en un espacio didáctico para compartir historias intergeneracionales ${ }^{17}$. En él, pequeños y mayores, adolescentes y adultos, han tenido oportunidad de dialogar con el patrimonio de la escuela a través de distintas propuestas y actividades didácticas de carácter creativo, concebidas para posibilitar que todos pudieran

\footnotetext{
${ }^{16} \mathrm{Cfr}$. http://institucional.us.es/museopedagogia Página web del museo pedagógico.

${ }^{17} \mathrm{Cfr}$. https://www.youtube.com/watch?v=ul7gRnyLtpI Documental: El Museo Pedagógico de la Facultad de Ciencias de la Educación de la Universidad de Sevilla: un espacio para compartir historias.
} 
acercarse al pasado de la educación a través del conocimiento de la cultura material e inmaterial de la escuela.

En este sentido, la pedagogía de la estampa histórico educativa, tiene que ver con el constructo teórico y experiencial que se ha generado a partir de un proyecto didáctico que venimos desarrollando en el museo pedagógico y desde su fundación, con los estudiantes de las asignaturas "Historia de la Educación Contemporánea" en el Grado en Pedagogía y "Corrientes Contemporáneas de la Educación. Implicaciones en la etapa infantil", en el Grado en Educación Infantil de la Universidad de Sevilla. Hasta la fecha, en torno a 1500 estudiantes han participado directamente de esta experiencia.

Las estampas histórico educativas se conciben como un potente y atractivo recurso didáctico, especialmente apropiado para sensibilizar al alumnado universitario en la recuperación del patrimonio y memoria de la escuela. Esta práctica metodológica se ejecuta con la intención de conseguir aprendizajes más significativos vinculados con las asignaturas ligadas a la Historia de la Educación como área de conocimiento. La estampa la entendemos como una reproducción de una fotografía a partir de una modesta performance. La práctica consiste en la recreación de antiguas fotografías educativas/escolares extraídas de álbumes familiares que permitan rescatar vivencialmente imágenes del pasado escolar, acontecimientos sociales o estilos de vida de antaño, preservando así la fuerza de los instantes para aumentar su pervivencia (ÁLVAREZ y REBOLLO, 2016). Recrear estampas histórico educativas conlleva una acción poética, que parte de un extrañamiento, que conmueve, que fomenta la curiosidad y la sensibilidad hacia lo que nos rodea (o hacia aquello de lo que provenimos), que incita a la investigación, a probar y explorar ideas, a reunir información y a tomar decisiones. Significa, por ende, aprender a mirar de otra manera y a hacer descripciones nuevas de carácter interpretativo. A través de la recreación de estas estampas, los estudiantes se implican conscientemente en la construcción de una imagen. Se convierten en sujetos activos de la misma, y, a la vez, en objeto. Ellos mismos preparan el escenario, posicionan la cámara, y gracias al disparador automático, se colocan delante de ella (GENARO GARCÍA, 2012, p. 271). Y todo este trabajo creativo -como bien apunta Trachana (2013)- se convierte en centro del aprendizaje universitario. El museo pedagógico a través de su archivo fotográfico escolar, se presenta como fuente para la investigación histórica educativa de cuantos estudiantes participan en esta experiencia didáctica.

Este proyecto pedagógico, entendido como una oficina de recreaciones fotográficas, se basa en el principio de "retratar de nuevo para reinterpretar el pasado escolar" y sus principales objetivos se concretan en: a) Contribuir en el desarrollo de modelos de buenas 
prácticas de educación patrimonial en museos pedagógicos, y b) Crear conciencia patrimonial individual/colectiva de carácter histórico educativa entre los estudiantes de ciencias de la educación y sus entornos personales/familiares más próximos. De esta forma, a través de estos planteamientos didácticos, se propicia la recreación desde el presente de fotografías de la escuela del ayer, con el fin de participar en la conservación y exhibición de una muestra importante del patrimonio de la educación.

La filosofía del caso didáctico que nos ocupa, se centra en el estudiante/visitante del museo pedagógico como protagonista de los procesos de enseñanza aprendizaje a los que se desea hacer frente. El alumno se convierte en autor y actor de sus propios proyectos (COLOM, 2012). En esta línea, el profesor se convierte en un guía capaz de poner en contacto a los conocimientos histórico educativos con las experiencias previas del alumnado, para posibilitar así un aprendizaje novedoso y significativo. Despertar el interés y la motivación del alumnado hacia el aprender y el conocer es siempre una sana práctica que nos permite emprender propuestas pedagógicas de mayor rendimiento. Si la creatividad constituye el principio didáctico sobre el que gira toda nuestra acción educativa en el marco del museo pedagógico, la enseñanza a través del arte de acción y la representación puede presentarse como una atractiva forma de posibilitar el desarrollo de esta capacidad, que ha de aspirar a la construcción de un pensamiento crítico y divergente. De esta forma, la investigación en Historia de la Educación constituye en sí misma una manera de descubrir el pasado a través de la creatividad y la expresión artística. Así, el trabajo en equipo se presenta como un importante eje metodológico y organizativo del trabajo en el aula, que nos permite aprender e interactuar conjuntamente a través de los principios de cooperación, compañerismo, solidaridad, empatía, etc. (GOMÉZ ARCOS, 2005).

En concreto, para la recreación de fotografías escolares, desarrollamos un proceso didáctico que transcurre de la siguiente forma. En grupos de 3/4 personas, el alumnado elige varias fotos antiguas (entre 3 y 4) de escenas educativas (familiares, escolares, lúdicas, festivas, personales, etc.), que encuentren entre sus familiares y/o conocidos. Realizada esta tarea, el reto está en tratar de encontrarle sentido a todo lo que se ve en las mismas, analizándose cada uno de los elementos que ellas aparecen. Con ayuda de familiares y a través de entrevistas, los estudiantes tienen que preguntarse por el significado de la fotografía, por su intrahistoria y por el sentido de los elementos y/o materiales que en ellas aparecen ${ }^{18}$.

\footnotetext{
${ }^{18}$ El alumnado ha de tratar de responder a preguntas como: ¿cuál es el tamaño de la foto, qué medidas tiene?; ¿dónde y cuándo se hizo?; ¿quién la tomó?; ¿se conoce el título de la foto?; ¿qué momento se representa?; ¿tiene leyenda en su parte trasera?; ¿a qué temática alude?; ¿quiénes la protagonizan?; ¿por qué motivos se tomó?; ¿qué 
Fruto de este trabajo, se elabora un dossier con toda la información obtenida y con el resultado de la recreación de las fotos seleccionadas. Para esa tarea, el alumnado tiene dos opciones: a) Se elige un escenario real o inventado y se disfraza personalmente, pudiendo contar incluso con la ayuda de otros compañeros actores; y b) Se cuenta con la ayuda de niños pequeños u otros familiares para representar las fotos seleccionadas. Culminada esta labor, se realizan las respectivas fotografías, primero en color y después en blanco y negro. Una vez hechas las fotos, se busca o construye un texto (poema, escrito, discurso, letra de canción, testimonio escolar, etc.), que deberá acompañar al resultado de las estampas histórico educativas, inspirando una emoción o un sentimiento.

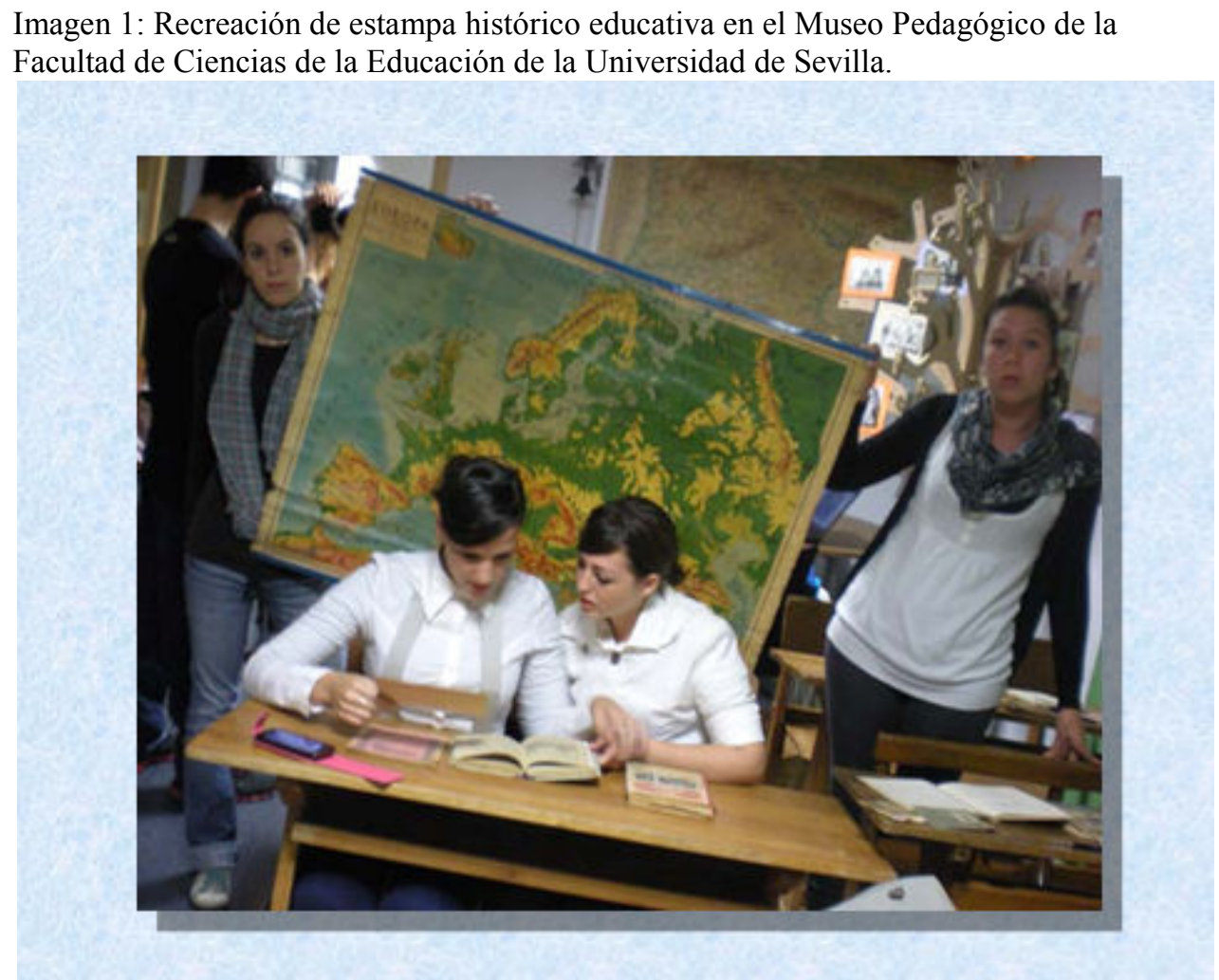

Fuente: colección particular del Museo Pedagógico de la Facultad de Ciencias de la Educación de la Universidad de Sevilla.

Llevadas a término las tareas señaladas, los estudiantes tienen que realizar una producción digital que dé cuenta tanto del resultado del trabajo, como del proceso seguido para finalizarlo. Como señala Pantoja Chaves (2010, p. 191), "no podemos olvidar que las tecnologías nos abren infinitas posibilidades para desarrollar la función esencial que los

aspectos protagonizan la foto?; ¿qué elementos aparecen en segundo plano?; ¿en qué lugar/espacio se desarrolla la acción?; ¿qué emociones/sentimientos provocan?; ¿la imagen representa una escena de la vida cotidiana, o está manipulada?; ¿se trata de una foto oficial o casera?; ¿cuál es su estado de conservación, dónde se conserva y quién?, ¿qué temas histórico educativos se pueden estudiar a través de ella? etc. (JULIE, 2014). 
historiadores hemos ejercido a través del tiempo: hacer memoria". El producto final del proyecto desarrollado deberá ser expuesto públicamente en clase y tras la exposición respectiva, los trabajos han de ser evaluados por un jurado compuesto por tres compañeros de clase y por el profesor como presidente del mismo. Los distintos componentes emiten una valoración/informe cualitativo del trabajo ejecutado, al que le sigue una calificación cuantitativa de entre 0 y 10 puntos. Cada grupo obtiene la puntuación correspondiente, fruto de hacer la media entre las calificaciones otorgadas por los compañeros y por el profesor.

En el marco de la asignatura en la que se desarrolla esta práctica pedagógica, el profesor ha de decidir qué porcentaje se le asigna a la elaboración de este trabajo en relación con el $100 \%$ de la calificación final. En nuestro caso, hemos asignado a esta práctica entre un 15 y un $25 \%$ de la calificación final, dependiendo del curso académico y de las circunstancias varias en las que la experiencia se ha materializado.

Este proyecto, del agrado de cuantos estudiantes participan en él, cuenta con un potencial pedagógico y creativo importante, tanto en cuanto permite que el alumnado aprenda a cuestionarse el hecho educativo desde una perspectiva crítica, interpretativa y activa. Al preguntársele a los participantes en este proyecto sobre el grado de satisfacción alcanzado en relación con su participación en el mismo -a través de un cuestionario pasado a una muestra de 500 alumnos-, un 92\% de los que responden valoran la experiencia con una puntuación media de 9,18 puntos, en relación con una escala de 0 a 10 puntos.

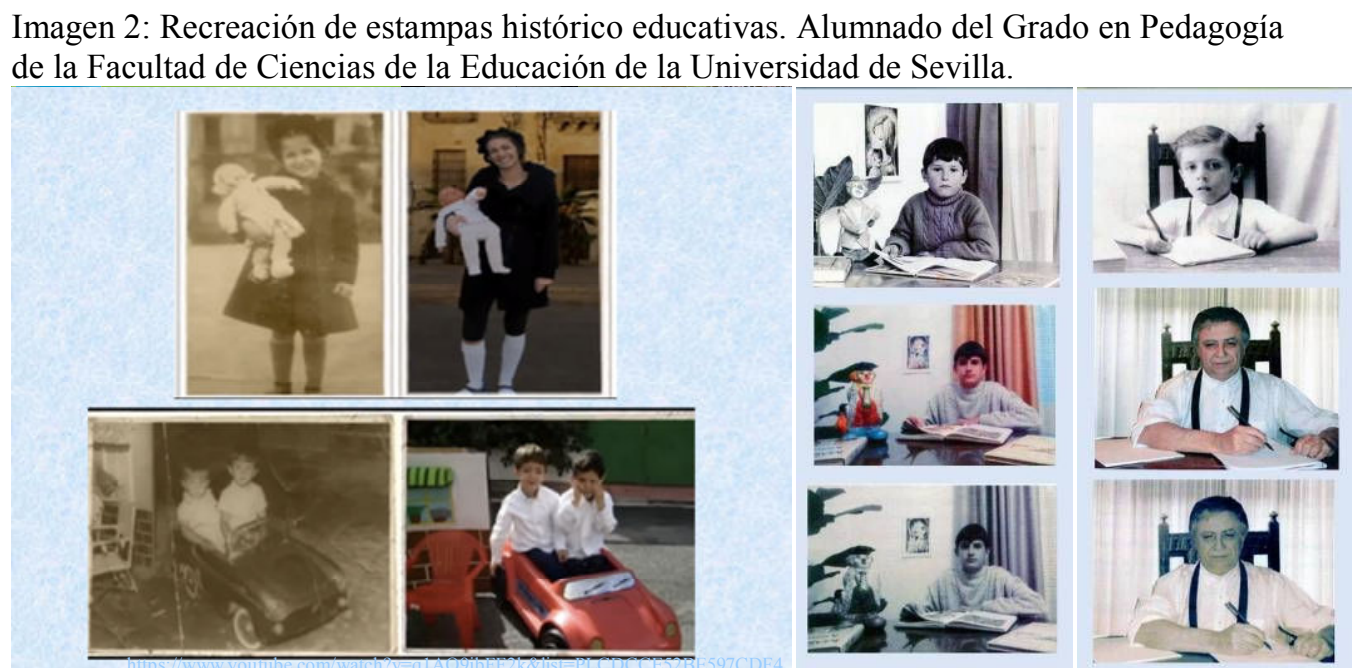

Fuente: colección particular del Museo Pedagógico de la Facultad de Ciencias de la Educación de la Universidad de Sevilla.

A continuación se presenta la ficha didáctica que nos permitirá desarrollar y aplicar la pedagogía de la estampa histórico educativa a la que nos hemos referido. 
Tabla 1: Estampas histórico educativas: recreación de fotografías escolares.

\begin{tabular}{|c|c|}
\hline $\begin{array}{l}\text { - Denominación de } \\
\text { la experiencia } \\
\text { didáctica: }\end{array}$ & $\begin{array}{l}\text { Estampas histórico educativas: } \\
\text { recreación de fotografias escolares }\end{array}$ \\
\hline $\begin{array}{l}\text { - Contextos de } \\
\text { aplicación: }\end{array}$ & $\begin{array}{l}\text { a) Museo Pedagógico. } \\
\text { b) Hogar familiar. } \\
\text { c) Aula universitaria. }\end{array}$ \\
\hline - Destinatarios: & $\begin{array}{l}\text { Estudiantes de Ciencias de la Educación. } \\
\text { Asignaturas adscritas al área de conocimiento de Historia de la Educación. }\end{array}$ \\
\hline $\begin{array}{l}\text { - Objetivos } \\
\text { específicos de la } \\
\text { propuesta: }\end{array}$ & $\begin{array}{l}\text { a) Seleccionar un conjunto de fotografías escolares y de otras escenas } \\
\text { educativas de carácter no formal, orientadas a estudiar a través de ellas una } \\
\text { parte importante de nuestro patrimonio histórico educativo. } \\
\text { b) Participar en la reinterpretación de fotografías escolares del ayer, a través } \\
\text { de estampas pedagógicas de carácter fotográfico. } \\
\text { c) Crear conciencia patrimonial desplegando en Youtube una base de datos } \\
\text { de vídeos que recojan un amplio conjunto de representaciones de fotografías } \\
\text { escolares de la escuela del ayer. }\end{array}$ \\
\hline $\begin{array}{l}\text { - Finalidades } \\
\text { generales: }\end{array}$ & $\begin{array}{l}\text { a) Propiciar una serie de reflexiones ligadas a la reconstrucción de la } \\
\text { memoria escolar y la identidad individual y colectiva. } \\
\text { b) Sensibilizar a los estudiantes en la necesidad de estudiar, salvaguardar y } \\
\text { poner en valor la recuperación del patrimonio inmaterial de la educación. } \\
\text { c) Empatizar con personas mayores de antiguas generaciones escolares, con } \\
\text { la intención de que sus testimonios formen parte de la memoria de la escuela. }\end{array}$ \\
\hline $\begin{array}{l}\text { - Competencias a } \\
\text { adquirir: }\end{array}$ & $\begin{array}{l}\text { a) Establecimiento de diálogos intergeneracionales entre escolares } \\
\text { pertenecientes a diferentes épocas. } \\
\text { b) Realización de entrevistas de contenido escolar a personas mayores. } \\
\text { c) Recreación histórica y artística en el presente de fotografías escolares del } \\
\text { ayer, a través de performance/representaciones dramáticas, que nos ayuden a } \\
\text { revivir acontecimientos, personajes y estilos de vida de una época escolar } \\
\text { determinada. }\end{array}$ \\
\hline $\begin{array}{l}\text { - Breve descripción } \\
\text { de la experiencia } \\
\text { (fases): }\end{array}$ & $\begin{array}{l}\text { a) Conformación de grupos libres de tres/cuatro personas. } \\
\text { b) Búsqueda y selección de fotos escolares antiguas (entre } 3 \text { y 4). } \\
\text { c) Análisis de las fotografías. Entrevistas y búsqueda de información. } \\
\text { d) Representación y recreación desde el presente de tres de las fotografías } \\
\text { seleccionadas. } \\
\text { e) Selección de textos para acompañar a la recreación de las fotos. } \\
\text { f) Elaboración de un dossier descriptivo/informativo sobre el trabajo } \\
\text { realizado. } \\
\text { g) Elaboración de un vídeo que muestre la recreación de las fotografias } \\
\text { representadas. } \\
\text { h) Exposición pública en clase. Valoración por parte de un jurado. }\end{array}$ \\
\hline - Temporalización: & Entre treinta y cuarenta y cinco días. \\
\hline $\begin{array}{l}\text { - Materiales y } \\
\text { recursos: }\end{array}$ & $\begin{array}{l}\text { a) Fotografias escolares antiguas. } \\
\text { b) Ropas y vestimentas de antaño. } \\
\text { c) Cámara fotográfica. } \\
\text { d) Recursos informáticos (ordenador, grabador DVD, etc.). }\end{array}$ \\
\hline - Evaluación: & Evaluación entre iguales (estudiantes) y evaluación externa (profesorado). \\
\hline - Referencia web: & $\begin{array}{l}\text { b) Canal Youtube de Patrimonio Educativo. } \\
\text { https://www.youtube.com/playlist?list=PLCDCCE52BE597CDF4 }\end{array}$ \\
\hline
\end{tabular}

Fuente: Elaboración propia. 


\section{CONCLUSIONES}

Estamos de acuerdo en que reaprender a mirar, a interpretar y a recrear fotografías escolares puede ayudarnos a reconstruir la historia de la escuela (FISCHMAN, 2006). De esta forma, el desarrollo y consolidación de una pedagogía de la estampa histórico educativa en el marco del Museo Pedagógico de la Facultad de Ciencias de la Educación de la Universidad de Sevilla, se presenta como una novedosa práctica didáctica que permite al estudiante de Ciencias de la Educación dialogar con el pasado de la educación desde el presente, a través de la acción creativa como potente recurso pedagógico.

La recreación de fotos escolares permite al alumnado pensar históricamente y cultivar la imaginación histórica, posibilitando un ejercicio empático que le invita a ponerse en el lugar de sus antepasados. El estudiante que participa de este proyecto, sin ser consciente de ello en muchas ocasiones, construye importantes discursos histórico educativos a través del análisis e interpretación de instantáneas fotográficas de la escuela del ayer. Si recrear es recordar, a través de esta práctica el alumno se encuentra con la oportunidad de desarrollar su memoria individual y colectiva. Así, la reconstrucción de estampas histórico educativas, o sea, el retorno a un patrimonio cultural como el fotográfico, nos obliga a mirar el pasado desde la contemporaneidad; se trata de un pasado que "nos mira, nos interpela, nos despierta afecto o rechazo, o nos engaña con su inocencia" (VELASCO, 2012, p. 20), pero que también nos enseña a valorarlo, comprenderlo y conservarlo, porque forma parte de nosotros mismos, de nuestra identidad individual e histórica, y de nuestro futuro.

El museo pedagógico, en la medida en que se preocupa por diseñar actividades y propuestas didácticas que ayuden al estudiante a reconstruir la genealogía personal, participa en hacer factible un aprendizaje más significativo, experiencial, vivencial y duradero. Se convierte así en un laboratorio crítico de análisis socioeducativo que permite visibilizar cuantos vínculos intergeneracionales se dan entre alumnado y familiares. En todo caso, la pedagogía de la estampa histórico educativa nos permite resucitar contextos y escenarios dormidos en el tiempo escolar, rellenando mudeces y deserciones; favorece la adquisición de competencias narrativas, orales, escritas, digitales e iconográficas; facilita el desarrollo de emociones y sentimientos; refuerza los conocimientos histórico educativos impartidos en la asignatura; favorece el trabajo heurístico y hermenéutico en la enseñanza de la historia de la educación y contribuye a conquistar a cuantos estudiantes se sienten negativamente atraídos por la enseñanza de la historia de la educación. 
No hay duda de que la historia de la educación es una disciplina en continuo proceso de desarrollo e innovación. Y en este sentido, el museo pedagógico está colaborando activamente en propiciar oportunidades innovadoras para conocer la historicidad del hecho educativo a través de su patrimonio.

El intercambio de experiencias y nuevas maneras de hacer la historia de la educación a través del estudio y difusión del patrimonio histórico educativo, así como el diálogo entre las posibles formas de enseñar y aprender la disciplina a través del ajuar etnográfico de la escuela, puede dar lugar a un avance significativo del área de conocimiento. El desarrollo de buenas prácticas educativas en las que el patrimonio de la escuela material e inmaterial se convierta en protagonista didáctico, sigue siendo una asignatura pendiente para los museos pedagógicos, que en estrecha relación con el profesorado de historia de la educación, han de ser capaces de poner al servicio de la comunidad una pedagogía de la estampa histórico educativa que nos ayude a descubrir nuestra identidad personal y colectiva. La interpretación del patrimonio de la escuela es una puerta abierta al conocimiento de la historia y a la construcción de nuestra memoria.

\section{REFERENCIAS}

AGUANA FIGUERA, Raúl. Introducción al estudio de la universidad como institución fundamental de la cultura en la civilización occidental. Caracas: Kindle Edition, 2013. 643 p.

ÁlvareZ domíngueZ, Pablo (coord.). Los Museos Pedagógicos en España: entre la memoria y la creatividad. Gijón: TREA Ediciones y Editorial Universidad de Sevilla (EUS), 2016a.

El museo de educación como centro de interpretación: revelar el sentido del patrimonio histórico educativo. En: DÁVILA, Paulí y NAYA, Luís María (coords). Espacios Educativos y Patrimonio Histórico Educativo. San Sebastián: Erein, p. 1219-1231, 2016b.

y REBOLLO ESPINOSA, M. José. Educación patrimonial en museos de educación. Creación y recreación de estampas histórico-educativas. En: AA.VV. Actas del III Congreso Internacional de Educación Patrimonial. Madrid: Comunidad de Madrid. Publicaciones Oficiales, 2016.

REBOLlO ESPINOSA, M. José y NúÑEZ GIL, Marina. El Museo Pedagógico de la Facultad de Ciencias de la Educación de la Universidad de Sevilla: una obra en tres actos. En: ÁlvareZ DOMÍNGUEZ, Pablo (coord.). Los Museos Pedagógicos en España: entre la memoria y la creatividad. Gijón: TREA Ediciones y Editorial Universidad de Sevilla (EUS), p.33-46, 2016. 
ARIÑO VILLARROYA, Antonio. Cambio de paradigma en la función cultural de la universidad. En: AA.VV. La extensión universitaria que viene. Estudio prospectivo de escenarios ideales. Universidades Públicas Andaluzas, p.15-44, 2007.

BARNETT, Ronal. Imagining the University. Routledge / Taylor \& Francis, 2013. 188p.

BIBLIOTECA NACIONAL DE MAESTROS. Programa Memoria De La Educación Argentina (MEDAR). La fotografía escolar como testimonio del pasado educativo para la construcción de un futuro: herramientas prácticas para su conservación y preservación. Buenos Aires: Biblioteca Nacional de Maestros, 2012.

BRUNELLI, Marta. Heritage Interpretation. Un nuovo approccio per l'Educazione al Patrimonio. Macerata: EUM Edizioni Università di Macerata, 2014a.

Las fotografías escolares como objetos sociales. Primeras reflexiones sobre el uso educativo y social del patrimonio en el museo de la escuela. En: BADANELLI, Ana M., POVEDA, María y RODRÍGUEZ, Carmen (coords.): Pedagogía Museística. Prácticas, usos didácticos e investigación del patrimonio educativo. Madrid: UCM y SEPHE, p.203-217, 2014b.

CEBREIRO LÓPEZ, Beatriz y FERNÁNDEZ MORANTE, $\mathrm{M}^{\mathrm{a}}$. Carmen. Estudio de casos. En: SALVADOR MATA, Francisco; J. L. RODRÍGUEZ DIÉGUEZ, José Luís y BOLÍVAR BOTIA, Antonio. Diccionario enciclopédico de didáctica. Málaga: Aljibe, 2004. 665p.

COLOM, Antoni J. y otros. Creatividad, educación e innovación: emprender la tarea de ser autor y no sólo actor de sus propios proyectos. Revista de Investigación en Educación, 10 (1), p.7-29, 2012.

DE LA TORRE, Saturnino. La universidad que queremos: estrategias creativas en el aula universitaria. Revista Digital Universitaria, 12 (10), 1-17, 2009.

DEL POZO ANDRÉS, María del Mar. Imágenes e Historia de la Educación: Construcción, reconstrucción y representación de las prácticas escolares en el aula. Historia de la Educación. Revista Interuniversitaria, 25, p.291-315, 2006.

y RABAZAS ROMERO, Teresa. Las imágenes fotográficas como fuente para el estudio de la cultura escolar: precisiones conceptuales y metodológicas. Revista de Ciencias de la Educación, 231-232, jul.-dic., p.401-414, 2012.

FISCHMAN, Gustavo Enrique. Las fotos escolares como analizadores en la investigación educativa. Educação \& Realidade, 31 (2), julio-diciembre, p.79-94, 2006.

FISCHER, Ericka. La estética de lo performativo. Madrid: Abada Editores, 2011.

GENARO GARCÍA, Noemí. Autorretrato Fotográfico como memoria. Re-interpretación del álbum familiar. Aularia, 1 (2), p.271-278, 2012.

GOMÉZ ARCOS, José Ricardo. Posibilidades educativas de la performance en la enseñanza secundaria. Arte, individuo y sociedad, 17, p.115-132, 2005. 
GONZÁLEZ, Sara y COMAS, Francesca. Fotografía y construcción de la memoria escolar. History of Education \& Children's Literature, XI, 1, p.215-236, 2016.

GROSVENOR, Ian y ROUSMANIERE, Kate. El uso de materiales visuales en la investigación histórico-educativa. Revista Mexicana de Historia de la Educación, 8 (V), p.231-253, 2016.

HALBWACHS, Maurice. Les cadres sociaux de la mémoire. Paris: Librairie Félix Alcan, 1925.

JULIE, A. M. Fotografia e educação: o uso da fotografia na prática docente. Primus Vitam. Revista de Cièncias e Humanidades, 7, $2^{\circ}$ semestre, p.1-16, 2014.

LÓPEZ MARTÍN, Ramón. La escuela por dentro. Perspectiva de la cultura escolar en la España del siglo XX. Valencia: Universitat de Valéncia, 2001.

LOURENÇO, Marta y WILSON, Lydia. Scientific heritage: Reflections on its nature and new approaches to preservation, study and access. Studies in History and Philosophy of Science, 44 (4), p.744-753, 2013.

MAYORDOMO PÉREZ, Alejandro. Prólogo. En: ÁlVAREZ DOMÍNGUEZ, Pablo (coord.). Los Museos Pedagógicos en España: entre la memoria y la creatividad. Gijón: TREA Ediciones y Editorial Universidad de Sevilla (EUS), p.13-17, 2016.

MORALES MIRANDA, Jorge. ¿Centros de interpretación? Boletín Carpeta Informativa del Centro Nacional de Educación Ambiental - CENEAM, 1994.

PAYÀ RICO, Andrés y ÁlVAREZ DOMÍNGUEZ, Pablo. Història de l'educació 2.0 i Història de l'e-educació. Les TIC i les xarxes socials al servei de la docència historicoeducativa. Educació i Historia. Revista d'Història de l'educació, 25, enero-junio, p.41-64, 2015.

PANTOJA CHAVES, Antonio. La fotografía como recurso para la didáctica de la Historia. Tejuelo, 9, p.179-194, 2010.

PINTO, Helena. Educação patrimonial e educação histórica: contributos para um diálogo interidentitário na construção de significado sobre o pasado. Diálogos, 19 (1), p.199-220, jan./abr. 2015.

RIEGO, Bernardo. Memorias de la mirada: las imágenes como fenómeno cultural en la España contemporánea. Santander: Fundación Marcelino Botín, 2001.

SANCHIDRIÁN BLANCO, Carmen. El uso de imágenes en la investigación históricoeducativa. Revista de Investigación Educativa, 29 (2), p.295-309, 2011.

SOUBIRAN, Sébastien. Patrimoine des universités et médiation scientifique. La Lettre de I'OCIM, 109, p.33-41, janvier-février 2007.

STAKE, Robert E. Investigación con estudio de casos. Madrid: Morata, 2005. 
TRACHANA, Angelique. Aprender lúdicamente. Juego y performance para impulsar la innovación y la creatividad en la Universidad. Revista Iberoamericana de Educación, 63, p.1-16, 2013.

VELASCO, Honorio M. Fotografías escolares, imágenes institucionales. Miradas retrospectivas a la fotografía en la escuela (1900-1970). En: BAUTISTA, Antonio y VELASCO, Honorio M. (coords.). Antropología audiovisual: medios e investigación en educación. Madrid: Editorial Trotta, S.A., p.15-34, 2012.

VILLA FERNÁNDEZ, Nuria. La historia de la educación desde la fotografía escolar: recuerdos y ausencias (1900-1970). En: PADRÒS, Nùria; COLLELLDEMONT, Eulàlia y SOLER, Joan (eds.). Actas del XVIII Coloquio de Historia de la Educación: Arte, literatura y educación. Vic: Universitat de Vic - Universitat Central de Catalunya, p.462-478, 2015.

WALKER, Rob. La realización de estudios de casos en educación. Ética, teoría y procedimientos. En: DOCKRELL, W. B. y HAMILTON, David. Nuevas reflexiones sobre la investigación educativa. Madrid: Narcea, p.42-82, 1983.

YIN, Robert. Case Study Research. Design and Methods. London: SAGE, 1989. 